\title{
Evaluation of Projection Patterns in the Primary Olfactory System of Rainbow Trout
}

\author{
David R. Riddle and Bruce Oakley \\ Neuroscience Program and Department of Biology, University of Michigan, Ann Arbor, Michigan 48109
}

\begin{abstract}
Topographic projections are important for coding sensory information in the visual, auditory, and somatosensory systems but are of uncertain importance in the coding of olfactory information. We searched for topographic projections between olfactory receptor cells and the olfactory bulb of the rainbow trout Oncorhynchus mykiss. Anterograde axonal tracing with HRP revealed that the olfactory axons arising from discrete regions of the olfactory epithelium travel together within the olfactory nerve. The abrupt resorting and redistribution of these axons at the interface between the olfactory nerve and olfactory bulb imply that local cues control and organize axonal projections. The sites of termination of HRP-labeled axons in the glomerular layer could not be predicted from the location of their cell bodies in the periphery. Retrograde tracing with fluorescently labeled latex beads, injected into glomerular subregions as small as $1 \%$ of the total glomerular volume, labeled receptor cells dispersed throughout the olfactory epithelium. The distributions of labeled receptor cells were uncorrelated with the bulbar injection sites. Double-labeling experiments revealed that even widely separated sites in the glomerular layer receive axons from comingled populations of receptor cells. Hence, the evidence indicates that the spatial arrangement of olfactory receptor cells in the epithelium is not preserved in the termination of their axons in the olfactory bulb. We conclude that the primary olfactory in trout lacks point-to-point or regionally topographic organization and that the entire extent of the olfactory epithelium contributes axons to each region of the glomerular layer.
\end{abstract}

In many sensory systems, the axons of neurons that are close together in the periphery terminate near each other in the central target. Such topographic projections map the skin's surface in somatosensory systems, the visual field in the visual system, and tonal frequency in the auditory system (e.g., Rose, 1960; Wall and Dubner, 1972; Lynn, 1975; Aitkin et al., 1984; Udin and Fawcett, 1988). Thus, the coding of important features of cutaneous, visual, and auditory stimuli depends upon the spatial pattern of projections of peripheral receptors to their central target. A similar understanding of the organization of olfactory receptors and their connections to the brain is critical for understanding how the olfactory system analyzes odor stimuli.

\footnotetext{
Received Mar. 27, 1991; revised July 1, 1991; accepted July 9, 1991.

This work was supported in part by a Rackham predoctoral fellowship to D.R.R. We thank A. Lawton, L. Wong, and L. H. Wu for technical assistance. We are grateful to Dr. A. S. LaMantia for his comments on the manuscript.

Correspondence should be addressed to Dr. David R. Riddle, Department of Neurobiology, Duke University Medical Center, Box 3209, Durham, NC 27710. Copyright (C) 1991 Society for Neuroscience 0270-6474/91/113752-11\$05.00/0
}

Several investigators have searched for topographic maps in the olfactory system of mammals and amphibians. These studies have demonstrated that small clusters of olfactory receptor cells send their axons to widely divergent regions of the olfactory bulb. Primary olfactory projections also incorporate significant convergence, since a small region of the olfactory bulb can receive input from much of the olfactory epithelium. Despite the lack of the point-to-point precision characteristic of other sensory systems, several meticulous studies of rodents and rabbit have demonstrated consistent regional topography (Land et al., 1970; Land, 1973; Land and Shepherd, 1974; Costanzo and O'Connell, 1978; Astic and Saucier, 1986, 1988; Saucier and Astic, 1986; Astic et al., 1987). Somewhat contrasting results have indicated that in amphibians the olfactory epithelium maps to the olfactory bulb only along a single axis that differs across species (discussed in Duncan et al., 1990). The axons from the dorsal and ventral epithelial surfaces, respectively, map to the medial and lateral regions of the olfactory bulb of the frog Rana pipiens (Duncan et al., 1990), but the dorsal and ventral surfaces map along the rostrocaudal axis of the olfactory bulb of the newt Triturus cristatus and completely overlap in their projections to the bulb of the salamander Ambystoma punctatus (Dubois-Dauphin et al., 1981; MacKay-Sim and Nathan, 1984). In Ambystoma, the rostrocaudal axis of the olfactory epithelium maps to the ventrodorsal axis of the olfactory bulb (MacKay-Sim and Nathan, 1984). Thus, studies of urodeles and anurans reveal traces of regional topographic projections that vary across species (Costanzo and Mozell, 1976; Dubois-Dauphin et al., 1980, 1981; Mackay-Sim and Nathan, 1984; Kauer, 1987; Duncan et al., 1990).

We have investigated the organization of the projections of primary olfactory axons in an aquatic vertebrate, the rainbow trout (Oncorhynchus mykiss). If regional topography is a fundamental organizing principle of vertebrate olfactory systems, then it is likely to be present in salmonids, whose life histories are crucially dependent upon refined olfactory capabilities. The central importance of olfactory-mediated migration in salmonid reproductive strategies suggests an evolutionary history that has optimized the performance of this sensory system (Wisby and Hasler, 1954; Groves et al., 1968; Hara, 1970, 1973; Selset and Doving, 1980). Further, the orderly and consistent structure of the olfactory mucosa and the ready accessibility of the olfactory structures in salmonids facilitate mapping studies (Fig. 1). The olfactory mucosa in trout comprises a dozen or more petal-like lamellae radiating from the base of each of the bilaterally paired olfactory rosettes (Pfeiffer, 1963; Holl, 1965; Kleerkopcr, 1969). The axons of the olfactory receptor neurons in each rosette converge to form a single olfactory nerve that may exceed $1 \mathrm{~cm}$ in length in a $30 \mathrm{~cm}$ trout. 
In this investigation, we used anterograde axonal tracing with HRP to map the central projections of small regions of the olfactory mucosa, and retrograde tracing with fluorescent latex beads to determine the peripheral location of olfactory rcceptor neurons that project to small areas in the olfactory bulb. The results reveal such wide divergence and convergence in the primary olfactory projection in trout that the site of termination of olfactory axons in the olfactory bulb cannot be predicted from the location of their somata in the mucosa.

\section{Materials and Methods}

Twenty-two rainbow trout (Oncorhynchus mykiss), $15-30 \mathrm{~cm}$ in length, were obtained from the Spring Valley Trout Farm (Dexter, MI) and maintained for $1-16$ weeks at $14-17^{\circ} \mathrm{C}$ in 75 gallon aquaria. Thirteen trout were used for anterograde axonal tracing studies and nine for retrograde tracing studies.

\section{Anterograde labeling of olfactory receptor neurons}

Following anesthesia by immersion in water containing tricaine methane sulfonate (MS-222; $100 \mathrm{mg} /$ /iter), trout were wrapped in a wet towel, packed in ice, and immobilized in a polystyrene fish holder. Cold aquarium water containing MS-222 ( $80 \mathrm{mg} /$ liter) flowed across the gills during the surgical procedure. For focal application of HRP to small regions of the rosette, the nasal septum was removed bilaterally in 11 fish to expose the olfactory rosette at the base of each nasal pit. The nasal pit was dried with a cotton pledget, and one or two lamellae of the olfactory rosette were segregated from the adjacent lamellae by a small piece of Parafilm. Crystals of HRP (type VI, Sigma) were placed on the isolated lamellae. After allowing $15 \mathrm{~min}$ for the receptor cells to take up HRP, the nasal pit was rinsed well with home aquarium water. On each rosette, lamellae were labeled in one of three regions: antcrior lateral, lateral, or posterior medial. The right and left rosettes were labeled symmetrically in five fish and asymmetrically in six. In two other anesthetized fish, most of one olfactory mucosa was labeled with HRP. With the nasal septum intact, a small pledget of Gelfoam soaked in 5\% HRP was inserted through the anterior naris and placed against the olfactory rosette. The anterior and posterior nares were covered with a small piece of Parafilm and sealed with cyanoacrylate glue. All fish were revived from anesthesia by irrigating the gills with home aquarium water until vigorous opercular movements returned.

After a 3 week survival period, each fish was reanesthetized with MS222 and perfused transcardially with cold, heparinized, physiological saline followed by approximately $400 \mathrm{ml}$ of buffered $1 \%$ paraformaldehyde and $1.25 \%$ gluteraldehyde flowing for $30 \mathrm{~min}$. The fixative was followed by an equal volume of $10 \%$ sucrose. The olfactory rosettes, olfactory nerves, and telencephalon with attached olfactory bulbs were removed, rinsed for several hours in $20 \%$ sucrose, and refrigerated overnight in $30 \%$ sucrose. Serial 20 or $30 \mu \mathrm{m}$ sections were cut on a cryostat and thaw mounted onto gelatin-subbed slides.

Mounted sections of the olfactory mucosae, nerves, and bulbs from all fish were reacted for HRP using tetramethyl benzidine (TMB; Mesulam, 1982). Alternate sections of the olfactory mucosae were reacted with metal intensified diaminobenzidine (DAB; Adams, 1981). Because of its higher sensitivity, the TMB procedure was used to determine the extent of HRP labeling in the olfactory rosette and to visualize labeled axons in the olfactory nerve and bulb. In the olfactory mucosa, the TMB procedure produced large crystals of reaction product that obscured much of the morphology of labeled cells. The DAB procedure produced a denser reaction product that permitted examination of the morphological detail of labeled cells.

Data analysis. One fish was excluded from the analysis of projection patterns because of extensive dispersion of HRP across most lamellae on each rosette. The remaining 20 olfactory bulbs from 10 fish were divided into three groups based upon the location of labeled lamellae in the ipsilateral olfactory rosette: anterior lateral $(N=5)$, lateral $(N=$ $8)$, or posterior $(N=7)$.

HRP-labeled fibers were traced by camera lucida under dark-field illumination. To decrease the number of drawings required to represent each olfactory bulb, we traced all of the HRP-filled axons in each consecutive set of three serial sections onto an outline drawing of the center section of each set. Thus, the patterns of labeled fibers in any two

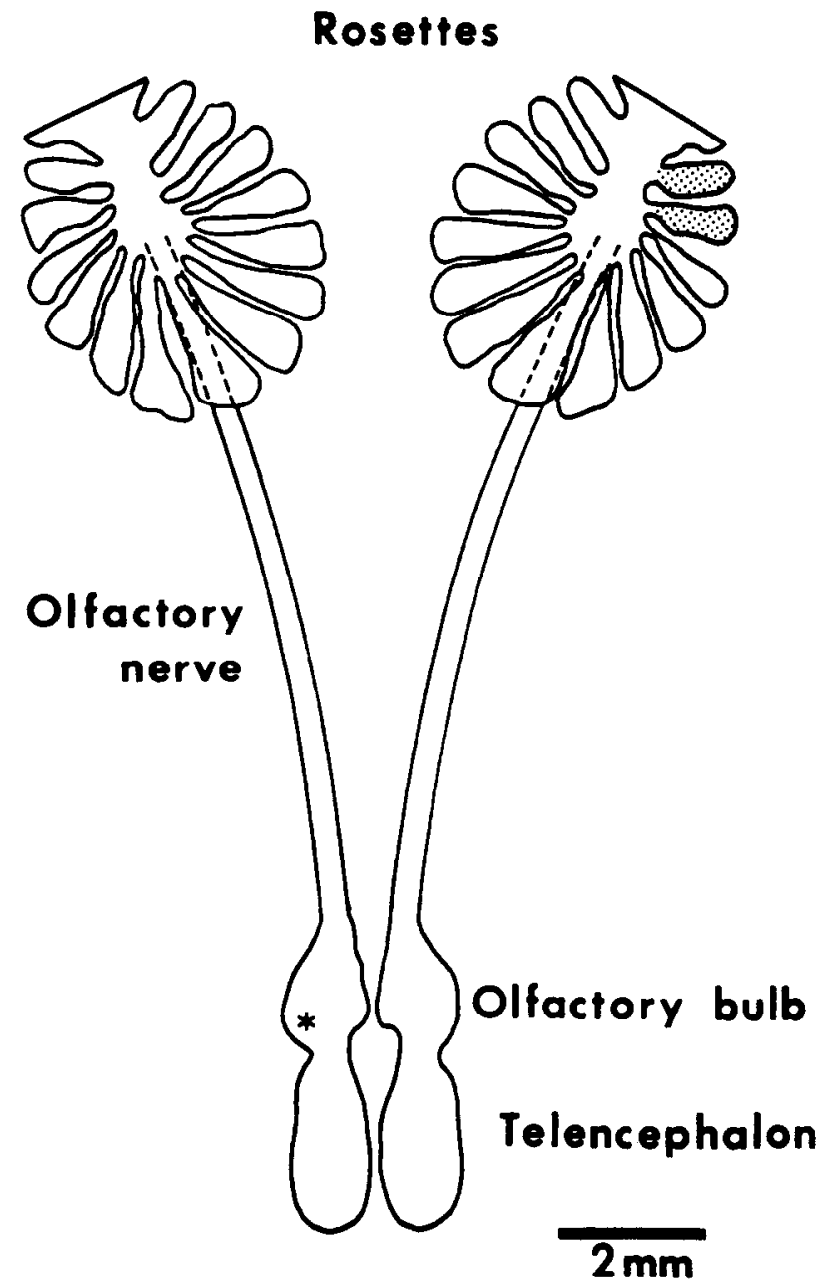

Figure 1. The primary olfactory system in trout. This composite of camera lucida drawings illustrates the primary olfactory system and forebrain of the rainbow trout. Patches of olfactory epithelium are located on the approximately 12-16 lamellae that radiate from the base of each olfactory rosette. A single olfactory nerve extends from the posterior ventral base of each rosette to the ipsilateral olfactory bulb. The slightly oval olfactory bulbs adjoin the telencephalon. For anterograde tracing, two to four adjacent lamellae were labeled with HRP (shaded areas). For retrograde tracing, a focal injection of fluorescent beads was placed in the olfactory bulb (e.g., at *).

olfactory bulbs could be compared subjectively by examining positionmatched drawings.

An alternative method of comparison provided a more objective analysis. The serial horizontal sections comprising each olfactory bulb were divided into 10 sets, representing $10 \%$ increments along the dorsalventral axis of the olfactory bulb. All of the labeled fibers in each set of histological sections were then traced onto the outline of the center section in the set. The most dorsal and most ventral of the 10 drawings were excluded from analysis because it was difficult to identify terminating fibers in those regions. To quantitate the distribution of labeled fibers, each of the remaining eight drawings was subdivided into four quadrants: anterior medial, anterior lateral, posterior medial, and posterior lateral. Thus, each olfactory bulb was divided into $8 \times 4=32$ spatial domains, each of which was scored for the presence or absence of HRP-labeled fibers in the glomerular layer. To evaluate the similarity of labeling in olfactory bulbs, we compared each of the 32 domains in one olfactory bulb with its corresponding domain in another bulb and calculated the total number of equivalent domains (i.e., those corresponding domains that were either both HRP positive or both HRP negative). $O$ equaled the observed number of equivalent domains. $E$ equaled the number of equivalent domains expected by chance and was calculated from $L$, the number of labeled domains in each olfactory 
Figure 2. Representative epithelial cells labeled by HRP applied to the olfactory rosette (metal-intensified DAB). Two distinct morphological types of HRP-filled cells are evident: cells with narrow dendrites that end in olfactory knobs (arrowheads) and those with broad apices that terminate flush with the epithelial surface (arrows). An axon (larger arrowhead in inset) extends from the soma of one such flat-headed cell. Scale bars, $30 \mu \mathrm{m}$ and $15 \mu \mathrm{m}$ (inset).

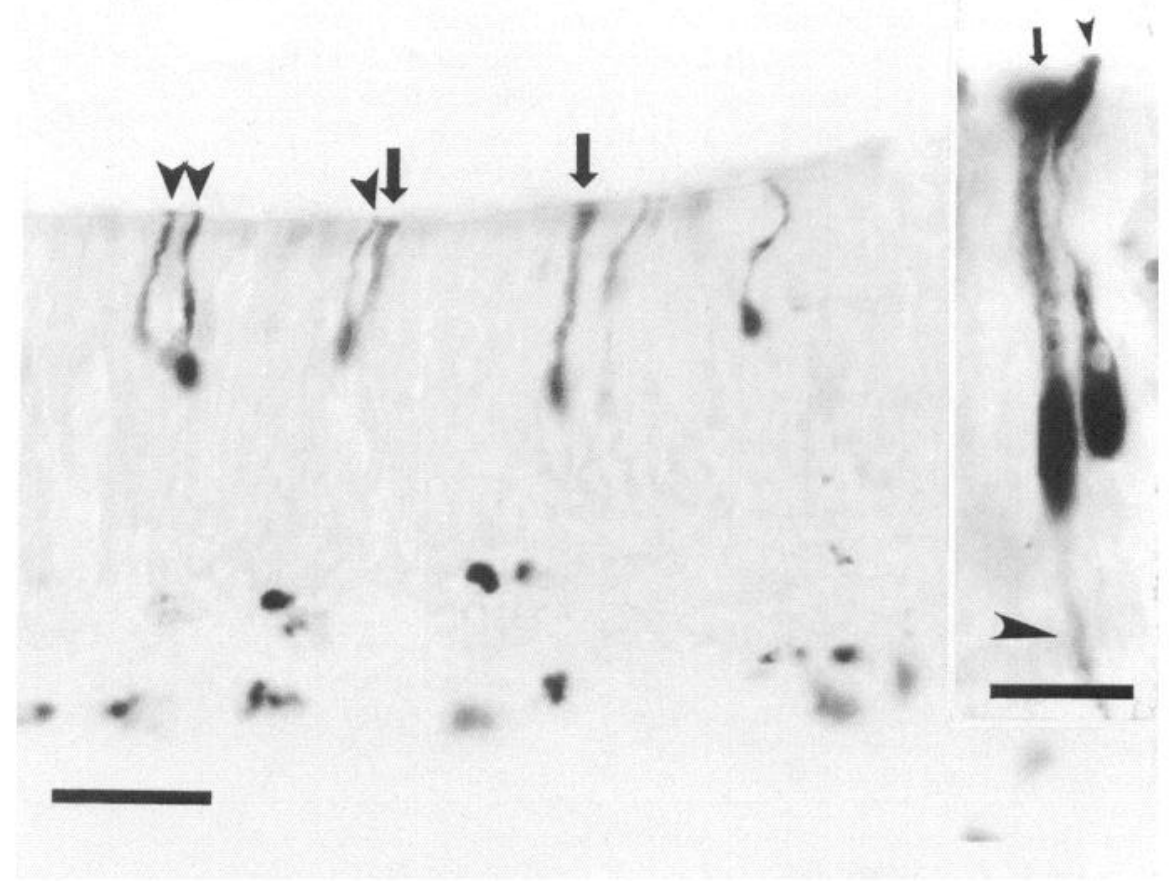

bulb, $a$ and $b$, according to the formula: $E=\left[\left(L_{a} \times L_{b}\right)+\left(32-L_{a} \times\right.\right.$ $\left.\left.32-L_{b}\right)\right] / 32$. Three sets of $\chi^{2}$ analyses were performed. First, olfactory bulbs from different fish labeled at the same mucosal site were paired at random, and $O$ and $E$ were determined and evaluated by a $\chi^{2}$ test. Second, $O$ and $E$ were compared for random pairings of olfactory bulbs from different fish with different mucosal sites labeled. Finally, $O$ and $E$ were determined for the two olfactory bulbs within each fish, and $\chi^{2}$ values calculated for the 5 fish with symmetrical labeling (same mucosal site in the left and right rosette), for the 5 fish with asymmetrical mucosal labeling, and for all 10 fish.

\section{Retrograde labeling of olfactory receptor neurons}

For retrograde axonal tracing, the trout were prepared for surgery as described above. The skull was exposed by a middorsal incision and a small hole was drilled at the midline at the level of the posterior margin of the orbit. After the hole was enlarged with fine rongeurs, each olfactory bulb was injected with fluorescently labeled latex microspheres (Lumafluor) using micropipettes with tip diameters of approximately 20 $\mu \mathrm{m}$. In seven fish, each olfactory bulb was double labeled; rhodamineconjugated and fluorescein isothiocyanate (FITC)-conjugated microspheres were injected into separate sites. In two other fish, a single injection of rhodamine beads was placed in each olfactory bulb. Injections were placed in one of four regions of the dorsal aspect of the olfactory bulb: anterior medial, anterior lateral, lateral, or posterior lateral. The hole in the skull was then filled with Gelfoam, and the skin was closed with nylon sutures (Ethilon).
Ten days after labeling, the fish were reanesthetized and perfused as in the anterograde tracing experiments, except the concentration of paraformaldehyde in the fixative was raised to $4 \%$ and the gluteraldehyde was omitted. The telencephalon and olfactory bulbs, olfactory nerves, and olfactory rosettes were removed and frozen in OCT embedding medium on dry ice. Serial $20 \mu$ m cryostat sections were cut, thaw mounted on gelatin-subbed slides, dried overnight, and coverslipped with DPX mounting medium. Sections were examined with a Zeiss epifluorescence microscope. The location and extent of the injection sites were determined from serial sections of each olfactory bulb. All rhodamine-labeled and FITC-labeled receptor neurons on each lamella were counted in serial sections of the olfactory rosettes. Counts of labeled cells were limited to every third section of three rosettes in which more than 20,000 cells were labeled. No correction was made for double-counted cells since the section thickness $(20 \mu \mathrm{m})$ was much greater than the average diameter of the labeled cells $(2-4 \mu \mathrm{m})$.

Data analysis. The olfactory rosettes were cut in the horizontal plane to provide serial cross sections of the lamellae from their distal tips to their proximal attachment at the base of the olfactory rosette. The numbers of rhodamine- and FITC-labeled receptor neurons on each lamella were recorded for every section of the olfactory rosette, producing a numerical matrix in which each entry specified the number of labeled olfactory receptor neurons (rhodamine or FITC) in a single section through one lamella of the olfactory rosette (one "lamellar section"). Thus, each matrix represented the spatial distribution of all receptor dendrites labeled by an injection of fluorescent beads into the olfactory bulb.

Figure 3. HRP labeling of olfactory axons. A, A longitudinal section of the olfactory nerve contains numerous peroxidase-labeled axons after application of HRP to the four anterior lateral lamellae of the olfactory rosette. The labeled axons remain in a discrete bundle (arrows) without further dispersion over the length of the nerve. $B$, Horizontal section of the posterior portion of the olfactory nerve $(O N)$ and the olfactory bulb $(O B) 3$ weeks after widespread application of HRP to much of the ipsilateral rosette. HRP-filled axons diverge through the olfactory nerve layer to terminate throughout the anterior (arrow) and lateral (arrowhead) glomerular layer. $C$, In this horizontal section of the olfactory nerve-olfactory bulb interface, it is clear that the HRP-labeled axons, originating in three contiguous lamellae, diverge widely as they enter the olfactory bulb. The close neighbor relationships evident in the nerve $(A)$ were not maintained as the axons enter the olfactory bulb; in some cases axons crossed the width of the olfactory nerve to enter the glomerular layer on the opposite side of the olfactory bulb (arrows). $D$, Axons labeled by focal application of HRP often terminated in groups of a few axons, forming roughly spherical basket endings. Note that the axons that terminate in this basket ending (arrowhead) approach by two different routes; some enter the glomerular layer $(G L)$ directly from the anterior olfactory nerve layer (ONL) (wide arrow), while others arc through the lateral nerve layer (large arrow) before leaving to enter the glomerular layer (small vertical arrow). Scale bars: $A$ and $C, 100 \mu \mathrm{m} ; B, 250 \mu \mathrm{m} ; D, 50 \mu \mathrm{m}$. 

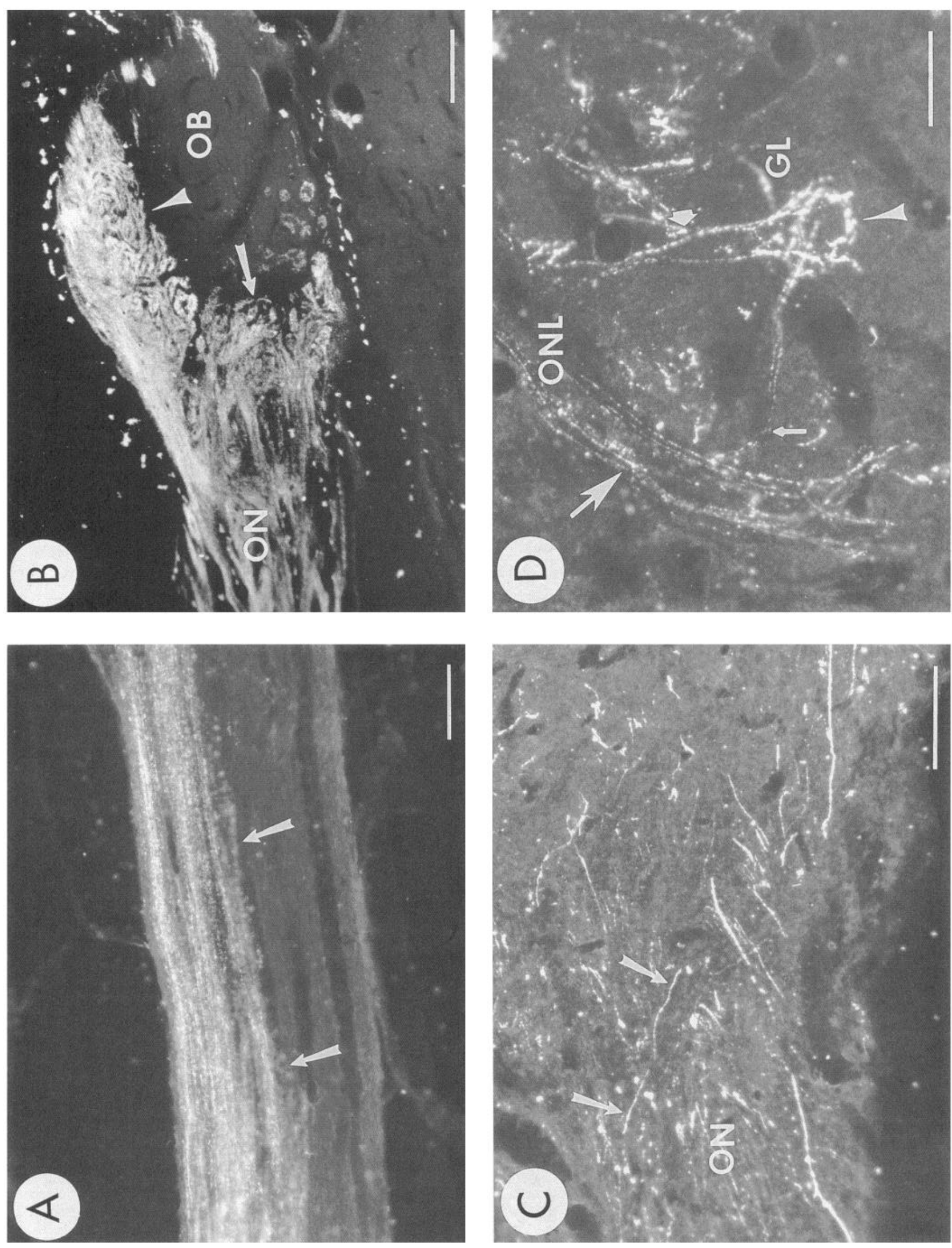


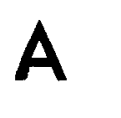

Figure 4. Patterns of labeled projections. HRP-filled axons in two olfactory bulbs are shown on compressed series of camera lucida drawings. Note that the axons could often be traced for extended distances; however, only the terminal portions were considered in the analysis of projection patterns (see Discussion). Each drawing represents a composite of three $30 \mu \mathrm{m}$ sections (see Materials and Methods); the series progress from dorsal (top) to ventral (bottom). A, Columns 1 and 2 contain corresponding drawings from the olfactory bulbs of two different fish in which the anterior lateral region of the ipsilateral olfactory rosette was labeled. Note that the patterns of labeled fibers in the two olfactory bulbs differ, particularly in the lateral (arrows) and posterior lateral (arrowheads) regions, which are heavily labeled in column 1 but not in column 2. B, Olfactory bulb in column $I$ is the same as in $A$, while column 2 is the contralateral olfactory bulb from the same fish. The two olfactory rosettes in this fish were labeled asymmetrically, one anterior laterally and the other posterior medially. Note that the patterns of labeled projections in $B$ are more similar than in $A$, even though disparate regions of the olfactory rosettes were labeled.

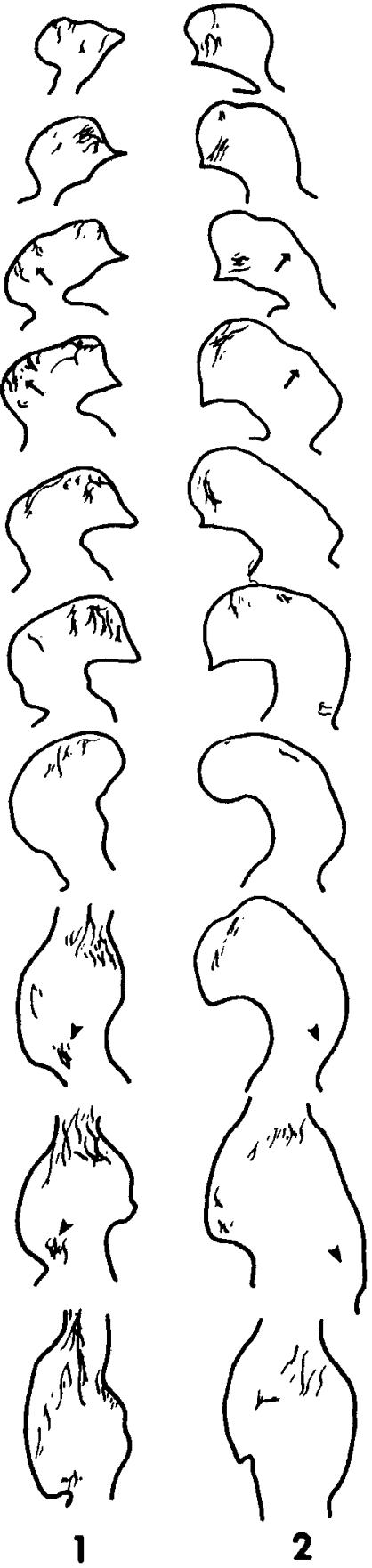

B
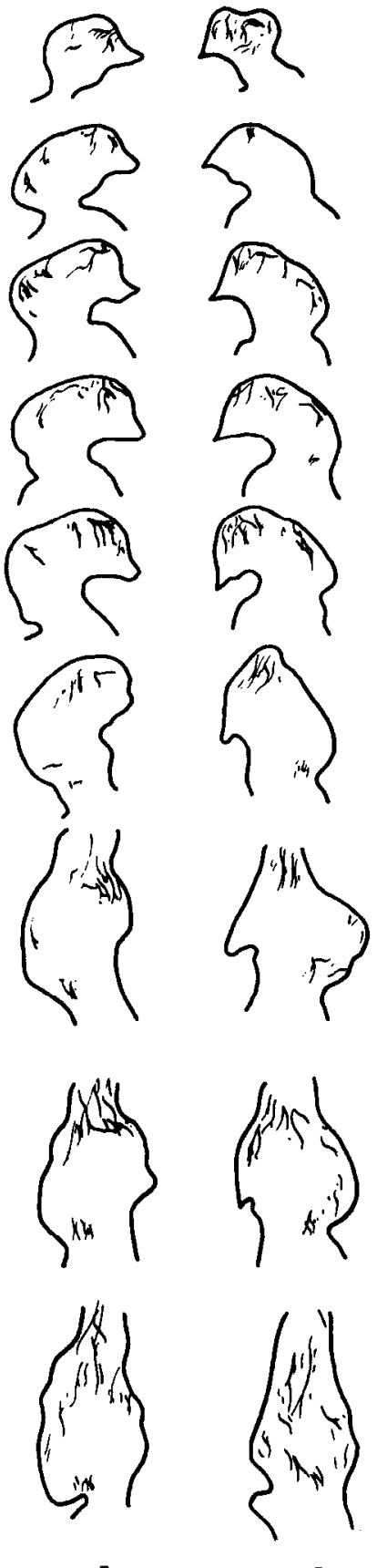

1
To evaluate the allocation of labeled cells among the lamellae of each rosette, we determined the percentage of labeled cells in the rosette that were located on each lamella. The consistent structure of the olfactory rosette permitted calculation of group data - that is, the mean percentage of all labeled cells found on corresponding lamellae in each of the four bulbar injection groups: anterior medial, anterior lateral, lateral, and posterior lateral.

To evaluate the distribution of labeled cells along the length of the lamellae, the sections comprising each lamella were divided into ten sets, each representing a $10 \%$ increment along the proximal-distal axis. For each lamella, we determined the percentage of labeled cells located in each $10 \%$ increment. The labeled cells on each rosette were similarly distributed along all lamellae; thus, we could sum the cell counts in corresponding $10 \%$ segments of all lamellae and calculate the percentage of labeled cells located in each $10 \%$ increment along the proximal-distal axis of each rosette. Mean values were calculated and compared for each of the four bulbar injection groups.

\section{Results}

\section{Anterograde labeling}

The apical extension of many HRP-labeled cclls cnded in a distinct ciliated knob 1-2 $\mu \mathrm{m}$ in diameter that extended slightly above the surface of the epithelium (arrowheads in Fig. 2). A second class of labeled cells had a wider apex, up to $4 \mu \mathrm{m}$ in diameter, that ended flush with the epithelial surface (arrows in Fig. 2). Both cell types had a narrow, basally directed axon and a broader apical dendrite. Cells of each class were often immediate neighbors (Fig. 2). Retrograde labeling with fluorescent beads provided independent verification that both classes of cells were olfactory receptor cells (see below).

HRP-labeled dendrites were restricted to two to four contig- 
uous lamellae after focal application of HRP to the rosette. Fascicles of HRP-labeled axons coursed along the core of the lamellae into the base of the rosette, where they joined unlabeled axons and entered the olfactory nerve. The HRP-filled axons remained in large, relatively cohesive bundles throughout the length of the olfactory nerve (Fig. $3 A$ ), with only modest dispersion as the axons progressed toward the olfactory bulb. When the nerve reached the olfactory bulb (Fig. $3 B$ ), the organization of the labeled axons changed dramatically; many axons abruptly altered their trajectories (Fig. 3C). Some axons traversed the width of the olfactory nerve, entering the olfactory nerve layer and glomerular layer on the opposite side of the olfactory bulb. Thus, the cohesiveness exhibited by labeled fibers in the olfactory nerve was disrupted by a realignment of axons into new fascicles that dispersed widely in the olfactory nerve layer. No HRP-filled fibers were evident in the contralateral olfactory bulb after extensive unilateral mucosal labeling in two fish.

From the medial, anterior, and lateral portions of the superficial nerve layer, labeled fibers could be seen penetrating into the deeper glomerular layer where they ended in roughly spherical terminal baskets approximately $20-40 \mu \mathrm{m}$ in diameter (Fig. $3 D$ ). Terminal baskets typically contained several axons, which could arrive from different directions (Fig. 3D). Most labeled axons terminated in the olfactory bulb, but some projected through the ventral olfactory bulb into the ventral medial telencephalon.

Spatial organization of primary afferent projections to the olfactory bulb. Axons labeled by focal application of HRP to the olfactory mucosa were always widely distributed throughout the glomerular layer; labeled axons were never restricted to a subregion of the glomerular layer (Fig. 4). The labeled projections were diffuse and apparently patternless, regardless of the location of HRP application in the mucosa. The most similar projection patterns were seen in the right and left olfactory bulbs of individual fish. Even when the comparison within an individual involved asymmetrical mucosal labeling, the projection patterns were more similar (Fig. $4 B$ ) than those between two fish with symmetrical labeling (Fig. $4 A$ ). Within individual fish, labeling homologous lamellae of the left and right rosettes did not increase the similarity of the bulbar projection patterns.

The quantitative analysis of the distribution of labeled fibers provided a more objective evaluation of projection patterns and clearly demonstrated the diffuse nature of the projections. In 18 of 20 olfactory bulbs, more than half of the 32 domains into which the glomerular layer was divided contained HRP-labeled terminals (mean $\pm 1 \mathrm{SD}=24 \pm 2$; range $=17-28$ domains). (The other two olfactory bulbs had labeled axons in the glomerular layer in 10 and 11 of the 32 domains, respectively.) The similarity of bulbar projection patterns, as assessed by labeling of corresponding domains in the olfactory bulbs of different individuals, was no greater with symmetrical mucosal labeling than with asymmetrical mucosal labeling $\left(\chi^{2}, p<0.3\right.$ vs $p<0.2)$. The indication from the composite drawings that the projection patterns were more similar in the two olfactory bulbs of fish in which the rosettes were asymmetrically labeled was confirmed by statistical analysis $\left(\chi^{2}, p<0.05\right)$.

\section{Retrograde labeling}

Each injection site in the olfactory bulb appeared as a region of bright fluorescence surrounded by a halo of dimmer fluorescence (Fig. 5A). The injection sites, including the halo, ranged in diameter from 100 to $400 \mu \mathrm{m}$ and in depth from 200 to $600 \mu \mathrm{m}$.
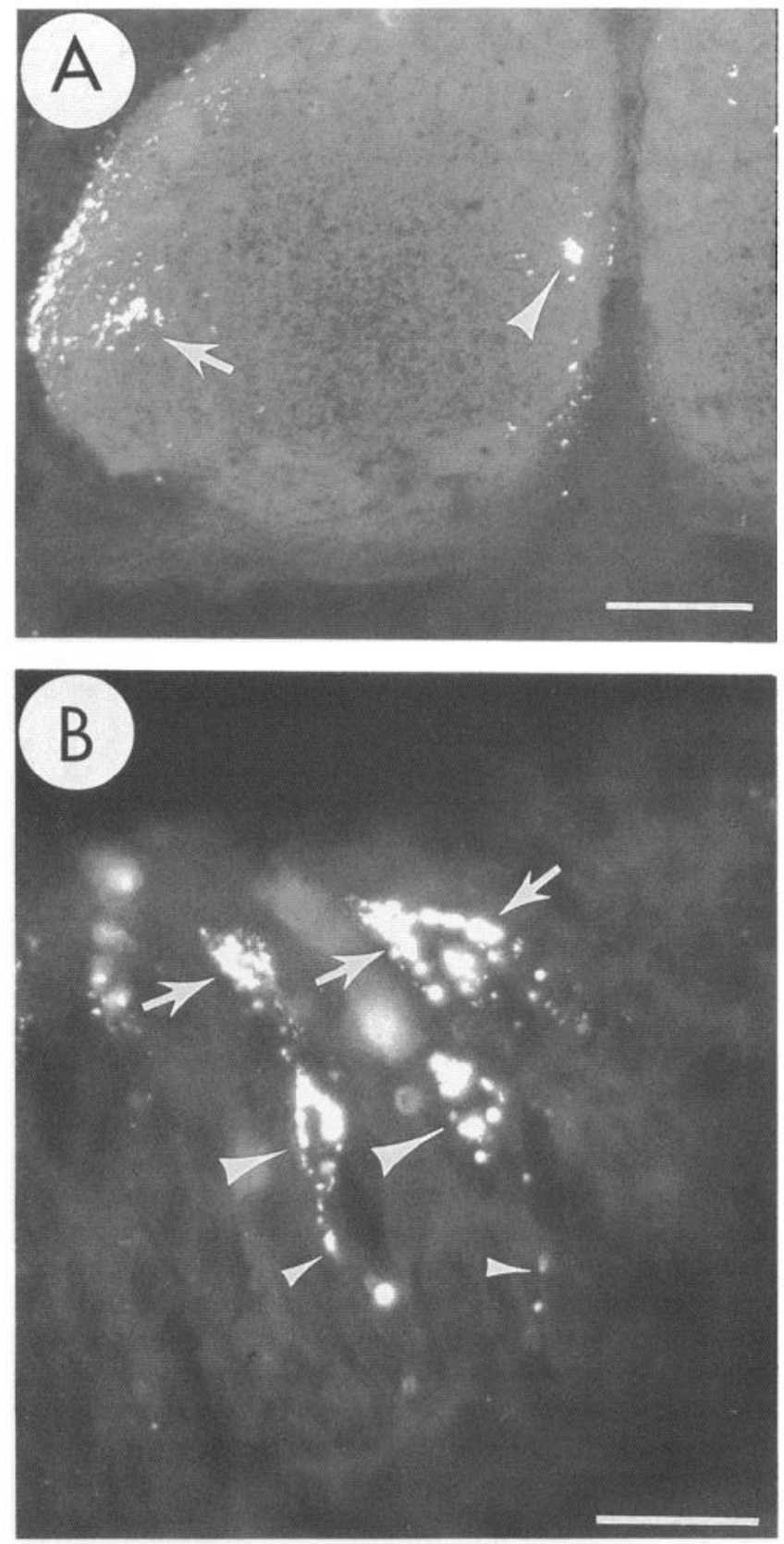

Figure 5. Retrograde labeling of olfactory receptor cells. $A$, Horizontal section through one olfactory bulb $10 \mathrm{~d}$ after injection of FITC- (arrow) and rhodamine-conjugated (arrowhead) latex beads (photographed with the FITC filter set). The complete extent of the FITC injection site is apparent, as is the pathway of beads transported anteriorly by axons in the olfactory nerve layer at the left margin of the olfactory bulb. The intensely fluorescent center of the rhodamine injection site bleeds through the FITC filters (arrowhead). The dim background fluorescence permitted us to determine that the injections were beneath the olfactory nerve layer and centered in the glomerular layer. $B$, Retrogradely labeled cells in the olfactory mucosa. The cells are identified as olfactory receptor neurons by their heavily labeled dendrites (arrows), the somal position (large arrowheads), and the basally directed axons (small arrowheads). Scale bars: $A, 500 \mu \mathrm{m} ; B, 10 \mu \mathrm{m}$.

Twenty-nine of the 32 injections were accurately placed in the glomerular layer. The glomerular layer injections were limited to the anterior medial, anterior lateral, lateral, or posterior lateral region of the dorsal half of the olfactory bulb. We estimate that the largest injections involved less than $10 \%$ of the glo- 
Figure 6. Distributions of labeled cells among lamellae. The mean ( \pm 1 SEM) percentages of all labeled receptor cells that were located on each lamella are shown for focal injections of fluorescent beads into the posterior lateral $(P L)$, lateral ( $L a t)$, anterior lateral $(A L)$, or anterior medial $(A M)$ olfactory bulb. The lamellae are designated by the side of the rosette, medial $(M)$ or lateral $(L)$, and by their position along the raphe from most posterior ( $I$ ) to most anterior (6). In each group, there are more labeled cells on the posterior lamellae (1-3) than on the anterior lamellae (4 6). There were no significant differences between any of the groups in the average percentage of labeled cells found on any of the lamellae (Student's $t$ tests, two-tailed, all $p>0.1$ ).

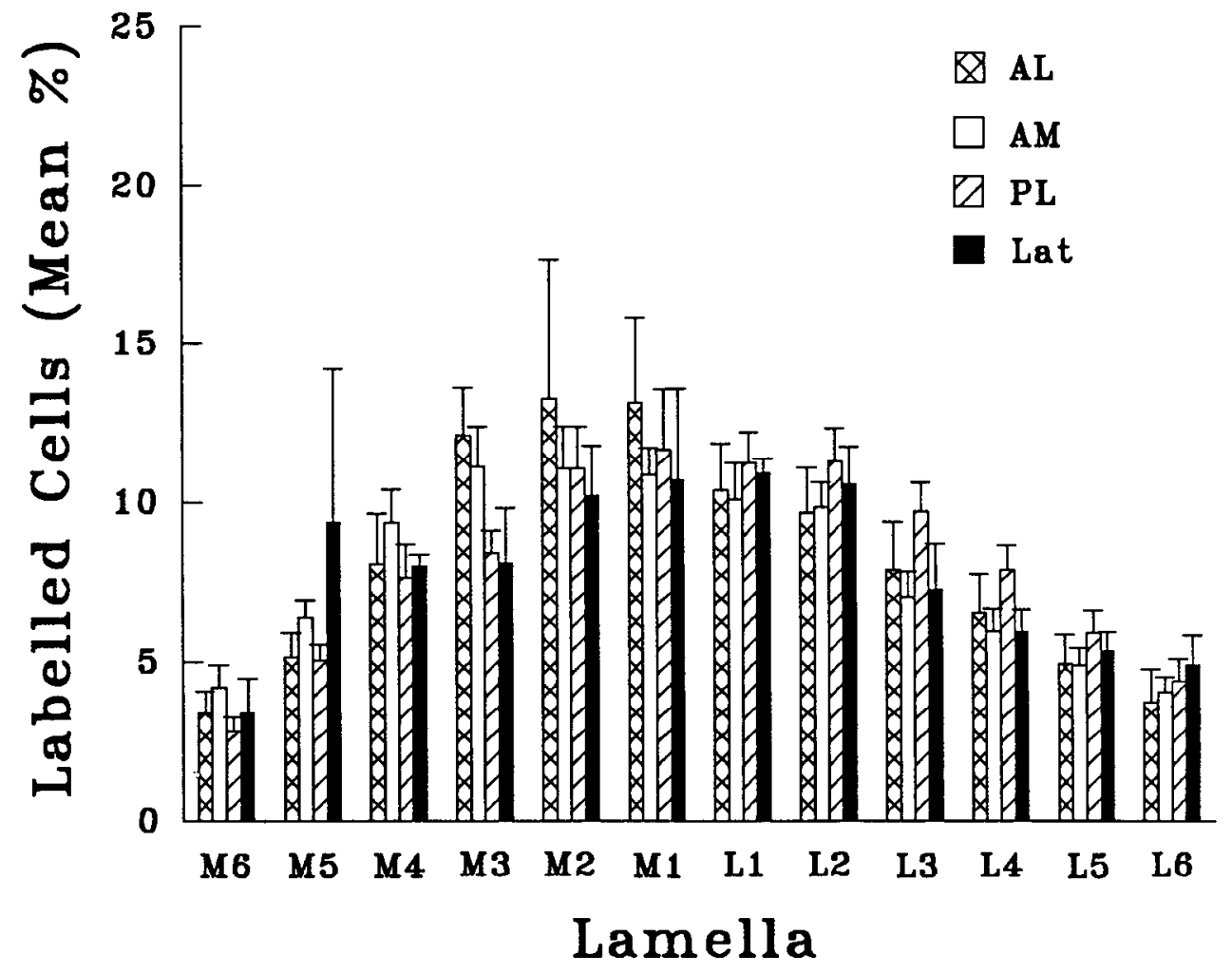

fish in which the rhodamine and FITC injection sites overlapped.

Twenty-seven of the 32 injections labeled receptor cells in the olfactory mucosa. The number of cells retrogradely labeled by a single injection ranged from fewer than 100 to 24,000 . Of the 27 successful injections, three labeled fewer than 100 cells, two between 100 and 1000 , ninc between 1000 and 5000 , three between 5000 and 10,000, four between 10,000 and 20,000 and six labeled more than 20,000 cells. Larger injections labeled more cells, but the number of labeled cells was not systematically related to the injection site. No labeled receptor cells were seen when the beads were limited to the meninges surrounding the olfactory bulb or when the injection site in the olfactory bulb was deep to the glomerular layer.

Spatial distribution of retrogradely labeled cells. Labeled receptor neurons were widely dispersed in the olfactory rosette after every successful injection. Twenty-six of the 27 successful injections labeled receptor neurons on every lamella of the olfactory rosette. In the remaining instance, 13 of 14 lamellae bore labeled cells, although only 46 receptor cells were labeled in the entire olfactory rosette. The larger posterior lamellae generally contained more labeled receptor cells than the smaller anterior lamcllac, but the mean percentage of labeled receptor neurons located on each lamella of the olfactory rosette was not significantly different among injection groups (Student's $t$ tests, all $p$ $>0.1$; Fig. 6). The variation in distribution over the rosette was as great for injections in the same part of the olfactory bulb (within a group) as for injections in different parts of the bulb (between groups).

The distribution of labeled receptor cells within each lamella was also analyzed. For the three smallest injections (fewer than 100 cells labeled), the labeled cells were widely scattered $-82 \%$ of the lamellar sections that contained labeled cells had only labeled cells by their orange-red color. Receptor cells containing both rhodamine and FITC beads were evident only in the single 

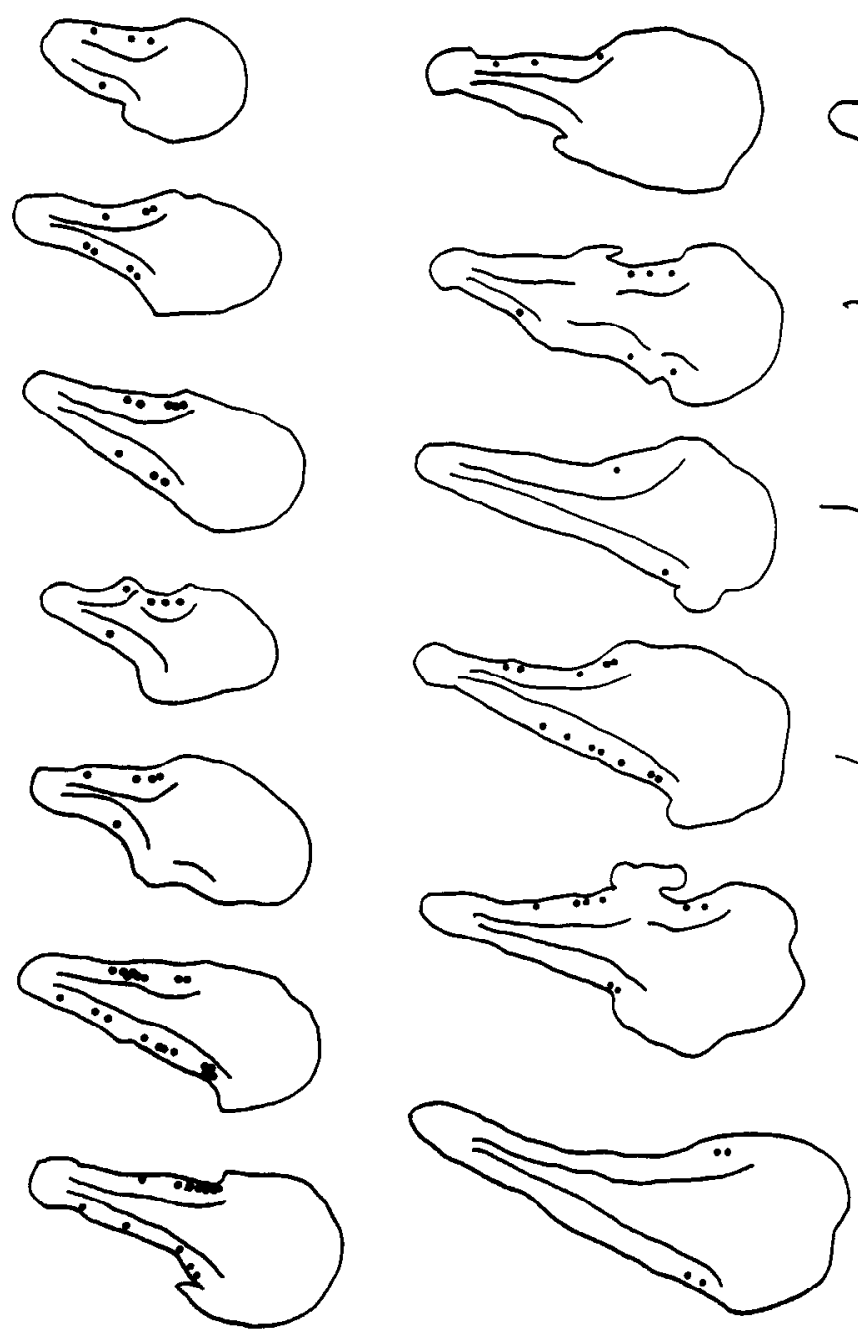
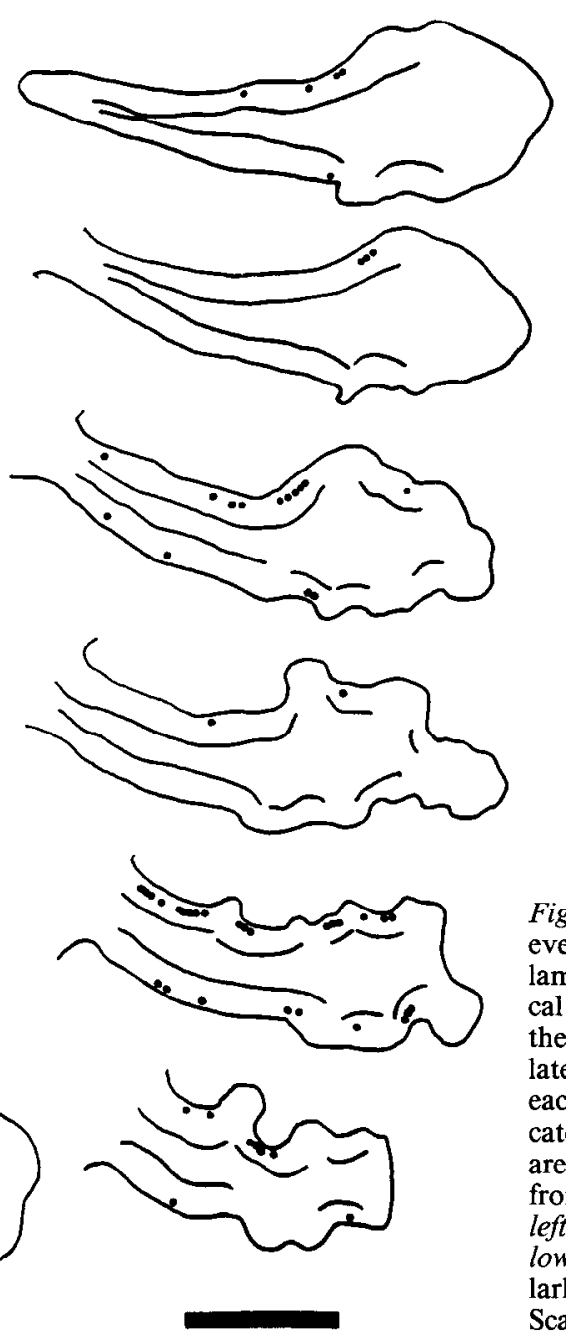

Figure 7. Camera lucida drawings of every fifth section of a representative lamella of the olfactory rosette, after focal injection of fluorescent beads into the anterior lateral region of the ipsilateral olfactory bulb. The position of each fluorescently labeled cell is indicated by a dot. Note that labeled cells are widely distributed on the lamella from the distal tip (drawing at upper left) to the proximal base (drawing at lower right). Labeled cells were similarly widely distributed on all lamellae. Scale bar, $500 \mu \mathrm{m}$. one such cell-but were more abundant in the distal regions of each lamella. In the remaining 24 rosettes, the labeled cells wcre widely distributed on each lamella from the distal tip to the proximal region near the core of the olfactory rosette (Fig. 7). There was often moderate clustering of labeled receptor cells at proximal, central, or distal sites along the proximal-distal lamellar axis, but the distribution of labeled cells along that axis did not change systematically with changes in the bulbar injection site. Since labeled cells were generally concentrated at similar levels along the proximal-distal axis of each lamella in a given rosette, the distribution of labeled cells along the proximal-distal axis of the rosette was determined (see Materials and Methods). There were no significant differences among groups in the mean percentage of labeled cells located in any of the 10 regions along the proximal-distal axis of the rosette (Student's $t$ tests, all $p>0.1$; Fig. 8). As with the distribution of labeled cells among a rosette's lamellae, the variation within each bulbar injection group was as great as the variation between injection groups. For each injection site, on average, labeled cells were rather evenly distributed along the proximal-distal axis of the lamellae, except in the most proximal and most distal 10\% where the area of the sensory epithelium is decreased (D. R. Riddle and B. Oakley, unpublished observations).
Nonoverlapping bulbar injections of rhodamine and FITC beads produccd highly intermingled populations of labeled receptor cells in the olfactory mucosa. The distributions of rhodamine-labeled and FITC-labeled receptor cells among the various lamellae of the rosette, as well as the distribution along the proximal-distal axis of the rosette, overlapped so substantially that it was impossible to determine from the distribution of beads in the rosette and individual lamellae whether the two injection sites had been close to each other (Fig. $9 B$ ) or widely separated in the olfactory bulb (Fig. $9 A$ ).

\section{Discussion}

The goal of these studies was to establish the spatial relationship between the locations of olfactory receptor neurons in the epithelium and of their terminals in the olfactory bulb. It was therefore important in the anterograde tracing studies to include in the analysis only the terminal portions of axons, excluding HRP-labeled fibers coursing in the olfactory nerve layer. Including such fibers of passage would have spuriously increased the apparent dispersion of receptor axons. Fortunately, terminating axons were easily identified by their depth beneath the surface of the olfactory bulb. The border between the olfactory nerve layer and the glomerular layer was easily distinguished 
Figure 8. Distributions of labeled cells within lamellae. The mean $( \pm 1$ SEM) percentage of all labeled receptor cells located in successive intervals equivalent to $10 \%$ of the distance along the proximal-distal axis of the lamellae (see Materials and Methods) for four injection groups: posterior lateral $(P L)$, lateral $(L a t)$, anterior lateral $(A L)$, and anterior medial $(A M)$. The mean percentage of labeled cells is similar at all levels along the proximal-distal axis except in the most distal and the most proximal $10 \%$. Pairwise comparisons between groups of the mean percentage of labeled cells located in each $10 \%$ of the lamellae revealed no significant differences (Student's $t$ test, two-tailed, all $p>0.1$ ).

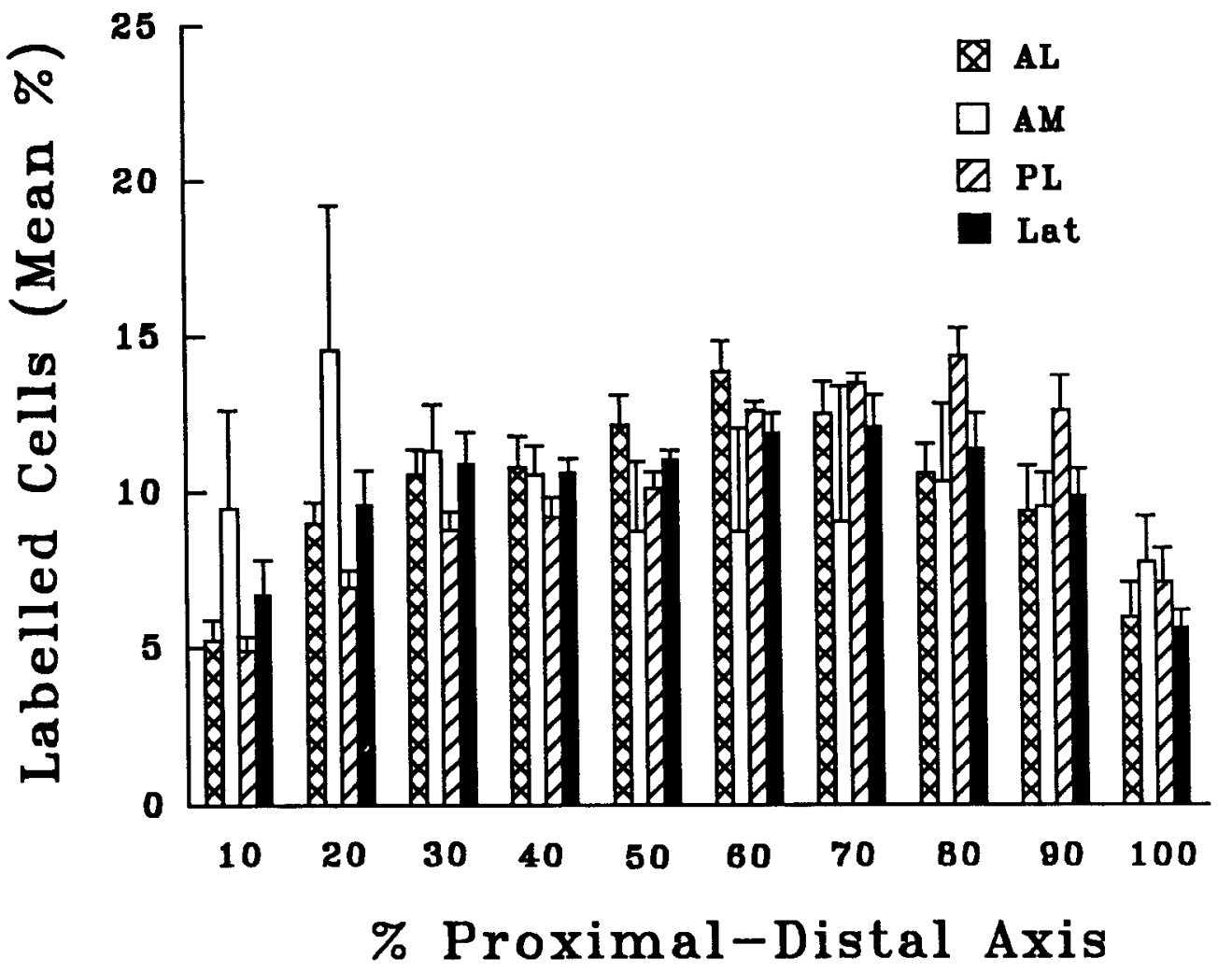

with phase-contrast illumination. It was clear that olfactory axons followed a largely radial trajectory from the olfactory nerve layer into the glomerular layer and terminated locally with little tangential displacement.

Since we labeled both rosettes in each fish, we considered the possibility that contralateral projections exaggerated the amount of axon dispersion in the olfactory bulb. Although limited contralateral projections have been reported in the olfactory bulb of Xenopus and Rana (Ebbesson et al., 1986; Duncan et al., 1990), HRP-labeled axons in the trout were restricted to the ipsilateral olfactory bulb after HRP had been extensively applied to one olfactory rosette in each of two fish. Evidently, the dispersed bulbar projections revealed by focal applications of HRP were strictly ipsilateral.

These experiments demonstrate that the organization of the primary olfactory system in trout is similar in some respects to that in other vertebrates. Our observation that axons from clustered receptor cells remained together within the olfactory nerve is consistent with reports of the organization of amphibian olfactory axons. Daston et al. (1990) followed small groups of HRP-labeled fibers through sequential cross sections of Rana olfactory nerve and found that axons that were neighbors in one cross section remained within the same fascicle over extended lengths of the nerve. Studies of the olfactory nerve in Ambystoma have shown that the axons in each small fascicle of the olfactory nerve arise from a restricted region of the olfactory mucosa yet have widespread terminations in the olfactory bulb (Kauer, 1981). We observed similar organization in the olfactory system of the trout, where the axons from small regions of the mucosa diverged to terminate throughout the glomerular layer. To judge from the abrupt changes in the trajectories of HRPlabeled axons when they reach the interface of the olfactory nerve and bulb, and from the wide dispersion within the olfactory nerve of axons fluorescently labeled by focal bulbar injection, olfactory axons in the trout appear to be rearranged over a very short distance in the nerve-bulb plexus. This abrupt rearrangement of axons implies that a new ordering principle is imposed in that region, whereby axons that were arranged in the nerve according to the location of their somata in the mucosa are redistributed in the bulb on the basis of other properties.

The redistribution of axons as they enter the olfactory bulb of the trout produces divergent-convergent connections that are qualitatively similar to those described in amphibians, though somewhat broader in scope (Costanzo and Mozell, 1976; Dubois-Dauphin et al., 1980, 1981; Mackay-Sim and Nathan, 1984; Kauer, 1987; Duncan et al., 1990). The functional significance of such organization, recently discussed by Kauer (1991), remains unclear. It is tempting to speculate, however, that scattered olfactory axons from receptor cells with similar response properties converge and terminate in functional foci in the glomerular layer, perhaps within individual glomeruli or small subregions. While there is as yet no direct evidence in fish for functional segregation at the level of the glomerulus, electrophysiological studies of salmonids have suggested significant functional segregation of axons in the olfactory bulb, where the lateral and medial regions respond differentially to amino acid and bile salt odors, respectively (Thommesen, 1978).

If regional topography like that described in amphibians and mammals is critical for information processing in the vertebrate olfactory system, it might be expected to be present in fish with a well-developed olfactory sense. Particularly, if the olfactory system in trout was topographically organized, one would expect that labeling homologous regions in two olfactory bulbs or mucosae would produce relatively similar patterns of labeled re- 


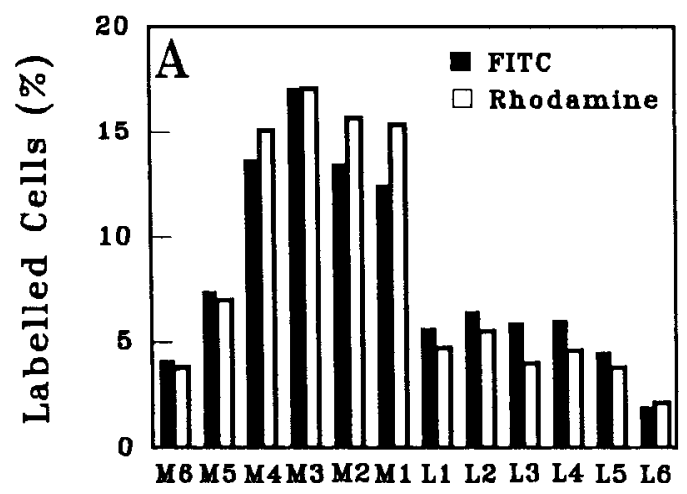

Lamella

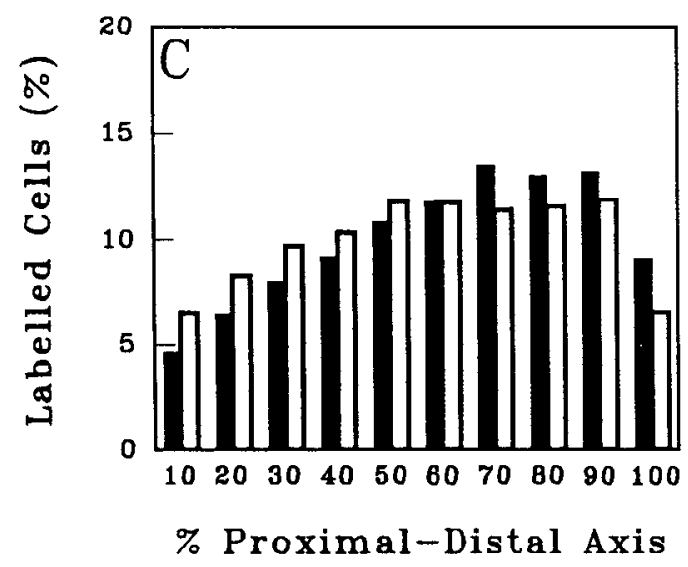

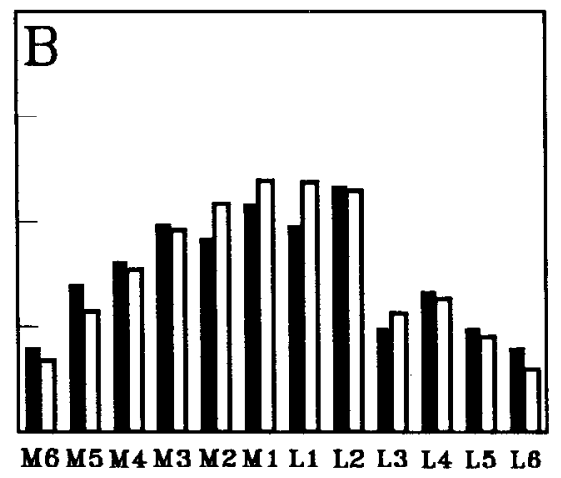

Lamella

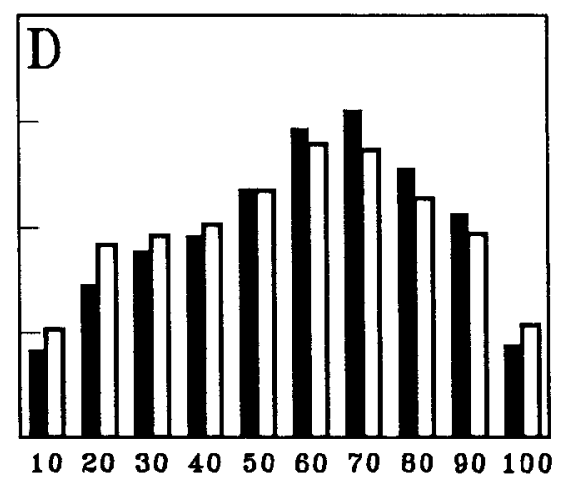

\% Proximal-Distal Axis
Figure 9. The distributions of labeled cells following dual injections of FITClabeled and rhodamine-labeled beads into two olfactory bulbs. The percentages of labeled cells found on each lamella of the olfactory rosettes $(A$ and $B$ ) and in each $10 \%$ interval along the proximal-distal axis of the rosettes $(C$ and $D$ ) are shown. It appears to make little difference whether the two injection sites were far apart (posterior lateral and anterior medial, $A$ and $C$ ) or close together (anterior lateral and anterior medial, $B$ and $D$ ). For both sets of injections, the distributions of rhodamine-labeled and FITC-labeled receptor cells were similar both among $(A$ and $B$ ) and within ( $C$ and $D$ ) the lamcllac. ceptor cells or axonal terminals, respectively, while labeling disparate regions would produce disimilar patterns. That was not the case. Focal application of HRP to homologous sites in two olfactory rosettes produced projection patterns in the corresponding olfactory bulbs that were neither more similar than expected by chance nor more similar than projections from disparate, nonhomologous regions of the mucosae. Correspondingly, the retrograde tracing experiments showed that the distributions of labeled cells, both among the lamellae (Fig. 6) and along the proximal-distal axis of lamellae (Fig. 8), were no more similar among individuals injected at homologous bulbar sites than among those injected at disparate sites. Moreover, after rhodamine- and FITC-conjugated beads were injected into the same olfactory bulb, rhodamine- and FITC-labeled receptor neurons were thoroughly intermingled and equally widely distributed whether the injection sites were close together or far apart (Fig. 9). Thus, the series of experiments supports the conclusion that little, if any, of the spatial organization of the receptor neurons in the olfactory mucosa of trout is maintained in the projections to the olfactory bulb. The scope of the divergent and convergent projections observed in this study reveals no evidence for even minimal regional topography; instead, the entire epithelium contributes axons to each region of the glomerular layer.

The present study raises new questions about the functional significance of the regional topography in mammalian olfactory projections. Saucier and Astic (1986) suggested that the topography in the mammalian system does not reflect a functional imperative, but rather that developing rat olfactory axons terminate in the nearest vacant region of the glomerular layer, and that the close spatial relationship between the olfactory mucosa and bulb and temporal factors in the ontogenesis of those structures are responsible for topography.

We have considered the possibility that small clusters of receptor cells might project to glomerular patches in a mosaic of such fine grain that even the smallest injections of fluorescent beads encroached upon several terminal regions. While difficult to reject completely, the extremely wide dispersion of fluorescently labeled receptor cells after every injection argues against such a hypothesis. The wide dispersion was best illustrated by the smallest bulbar injections, those least likely to involve multiple terminal regions. Three injections labeled regions no larger than a few glomeruli. The 40-100 receptor cells that were fluorescently labeled were so widely scattered that some were present on each lamella and virtually no lamellar section contained more than one labeled cell. The pattern of termination of anterogradely labeled fibers in the HRP study also argues against the concept of projections from aggregates of receptor cells to glomerular patches. As a rule, only a few axons in any individual glomerulus were labeled by focal application of HRP to small sites in the mucosa; the remaining axons in these partially labeled glomeruli presumably arose from other disparate (unlabeled) cells in the mucosa. Thus each glomerulus, perhaps the smallest region within the olfactory bulb that is clearly recognizable as a unit of organization, is innervated by widely dispersed, not locally clustered, receptor cells. 
This investigation has demonstrated that many, probably most, olfactory receptors in the trout make nontopographic projections to the olfactory bulb. Numerous axons project divergently from each small region of the olfactory mucosa to widespread areas of the olfactory bulb. Each small region within the glomerular layer receives convergent input from receptor neurons distributed throughout the olfactory mucosa. There appear to be local forces acting at the interface between the olfactory nerve and bulb that control the reassortment and redistribution of olfactory axons. Thus, while the olfactory system in trout appears to lack the point-to-point topographic arrangement that is preeminent in other sensory systems, the absence of such organization does not imply chaotic or primitive connections. It suggests that there are alternative organizational principles based upon properties of the olfactory receptor neurons that are unrelated to position. Further investigation to reveal the nature of the organization of connections between olfactory receptors and the brain may help to clarify how olfactory systems discriminate odor quality and intensity.

\section{References}

Adams JC (1981) Heavy metal intensification of DAB-based HRP reaction product. J Histochem Cytochem 29:775.

Aitkin LM, Irvine DRF, Webster WR (1984) Central neural mechanisms of hearing. Handb Physiol 3:675-737.

Astic L, Saucier D (1986) Anatomical mapping of the neuroepithelial projection to the olfactory bulb in the rat. Brain Res Bull 16:445454.

Astic L, Saucier D (1988) Topographical projection of the septal organ to the main olfactory bulb in rats: ontogenetic study. Dev Brain Res 42:297-303.

Astic L, Saucier D, Holley A (1987) Topographical relationships between olfactory receptor cells and glomerular foci in the rat olfactory bulb. Brain Res 424:144-152.

Costanzo RM, Mozell MM (1976) Electrophysiological evidence for a topographical projection of the nasal mucosa onto the olfactory bulb of the frog. J Gen Physiol 68:292-312.

Costanzo RM, O'Connell RJ (1978) Spatially organized projections of hamster olfactory nerves. Brain Res 139:327-332.

Daston MM, Adamek GD, Gesteland RC (1990) Ultrastructural organization of receptor cell axons in frog olfactory nerve. Brain Res 537:69-75.

Dubois-Dauphin M, Tribollet E, Dreifuss JJ (1980) Somatotopic organization of the primary olfactory pathway in the triton. J Physiol (Paris) 76:181-184.

Dubois-Dauphin M, Tribollet E, Dreifuss JJ (1981) Somatotopic relations between the olfactory mucosa and the olfactory bulb in the triton. Brain Res 219:269-287.

Duncan HJ, Nickell WT, Shipley MT, Gesteland RC (1990) Organization of projections from olfactory epithelium to olfactory bulb in the frog, Rana pipiens. J Comp Neurol 299:299-311.

Ebbesson SOE, Bazer GT, Jane JA (1986) Some primary olfactory axons project to the contralateral olfactory bulb in Xenopus laevis. Neurosci Lett 65:234-238.
Groves AB, Collins GB, Trefethen GB (1968) Roles of olfaction and vision in choice of spawning site by homing adult chinook salmon (Oncorhynchus tshawytscha). J Fish Res Board Can 25:867-876.

Hara TJ (1970) An electrophysiological basis for olfactory discrimination in homing salmon: a review. J Fish Res Board Can 27:565586.

Hara TJ (1970) Olfactory responses to amino acids in rainbow trout, Salmo gairdneri. Comp Biochem Physiol 54A:31-36.

Holl A (1965) Vergleichende morphologische und histologische untersuchugen am Geruchsorgan der Knockenfische. Z Morphol Oekol Tiere 54:707-782.

Kauer JS (1981) Olfactory receptor cell staining using horseradish peroxidase. Anat Rec 200:331-336.

Kauer JS (1987) Coding in the olfactory system. In: Neurobiology of taste and smell (Finger TE, Silver WL, eds), pp 205-231. New York: Wiley.

Kauer JS (1991) Contributions of topography and parallel processing to odor coding in the vertebrate olfactory pathway. Trends Neurosci 14:79-85.

Kleerkoper H (1969) Olfaction in fishes. Bloomington: Indiana UP.

Land LJ (1973) Localized projections of olfactory nerves to rabbit olfactory bulb. Brain Res 63:153-166.

Land LJ, Shepherd GM (1974) Autoradiographic analysis of olfactory receptor projections in the rabbit. Brain Res 70:506-510.

Land LJ, Eager RP, Shepherd GM (1970) Olfactory nerve projections to the olfactory bulb in rabbits: demonstration by means of a simple ammoniacal silver degeneration method. Brain Res 23:250-254.

Lynn B (1975) Somatosensory receptors and their CNS connections. Annu Rev Physiol 37:105-127.

Mackay-Sim A, Nathan MH (1984) The projection from the olfactory epithelium to the olfactory bulb in the salamander, Ambystoma tigrinum. Anat Embryol 170:93-97.

Mcsulam MM (1982) Tetramethyl benzidine for horseradish peroxidase neurohistochemistry: a non-carcinogenic blue reaction-product with superior sensitivity for visualizing neural afferents and efferents. J Histochem Cytochem 26:106-117.

Pfeiffer W (1963) Morphology of the olfactory organ in Pacific salmon (Oncorhynchus). Can J Zool 41:1233-1236.

Rose JE (1960) Organization of frequency sensitive neurons in the cochlear complex of the cat. In: Neural mechanisms of the auditory and vestibular systems (Rasmussen GL, Windle WF, eds), pp 116136. Springfield, IL: Thomas.

Saucier D, Astic L (1986) Analysis of the topographical organization of olfactory epithelium projections in the rat. Brain Res Bull 16:455462.

Selset R, Doving KB (1980) Behaviour of mature anadromous char (Salmo alpinus L.) towards odorants produced by smolts of their own population. Acta Physiol Scand 108:113-122.

Thommesen $G$ (1978) The spatial distribution of odour induced potentials in the olfactory bulb of char and trout (Salmonidae). Acta Physiol Scand 102:205-217.

Udin SB, Fawcett JW (1988) Formation of topographic maps. Annu Rev Neurosci 11:289-327.

Wall PD, Dubner R (1972) Somatosensory pathways. Annu Rev Physiol 34:315-336.

Wisby WJ, Hasler AD (1954) The effect of olfactory occlusion on migrating silver salmon (O. kisutch). J Fish Res Board Can 11:472478 . 